\title{
Antibacterial Properties of Essential Oil (EO) Extracted from Nigella sativa Linn. (Black cumin) and its Application Against Vibrio cholerae in Ground Chicken Meat
}

\author{
Sharmina Deloer ${ }^{1}$, M.L. Bari² ${ }^{2}$ and Md. Mahfuzul Hoque ${ }^{1 *}$ \\ ${ }^{1}$ Department of Microbiology, University of Dhaka, Dhaka-1000, Bangladesh, ${ }^{2}$ Center for Advanced Research in Sciences, University of Dhaka, Dhaka, 1000, \\ Bangladesh.
}

\begin{abstract}
Chemical preservatives for food preservation at high concentration are hazardous for public health. The natural antimicrobials from plants, herbs and spices have been given priority as alternatives of the chemical preservatives. In this study, antibacterial activity of the essential oil (3\%) from black cumin seeds was tested against five food borne pathogens viz Staphylococcus aureus (ATCC 25923), Shigella dysenteriae-I (MJ-84), Escherichia coli 0157:H7 (ATCC 12079), Escherichia coli (ATCC 25922) and Vibrio cholerae( ATCC 6395) using disc diffusion method. The essential oil (EO) showed antibacterial activity against both Gram positive and Gram negative bacteria with the highest inhibition against $S$. aureus $(17.4 \pm 0.2)$ and the lowest against Vibrio cholerae $(14.5 \pm 1.0)$. No activity was observed against $E$. coli and $E$. coli $0157: \mathrm{H} 7$. The effect of temperature and $\mathrm{pH}$ on the antibacterial activity of the EO from black cumin seeds was determined. $\mathrm{At} 100^{\circ} \mathrm{C}$ for $30 \mathrm{~min}$ treatment, no significant reduction of antibacterial activity of the EO was observed, suggesting that high temperature does not affect the activity. The optimum temperature for the activity was recorded at $50^{\circ} \mathrm{C}$. The $\mathrm{EO}$ showed the highest activity at $\mathrm{pH} 7.0$ (optimum) with an insignificant change of activity at pH 5.0, 9.0 and 10.0. Minimum inhibitory concentration (MIC) and minimum bactericidal concentration (MBC) of EO against $S$. aureus, $V$. cholerae and Shigella dysenterae were determined by two fold dilution method at optimum temperature of $50^{\circ} \mathrm{C}$ and $37^{\circ} \mathrm{C}$ and optimum pH at 7.0 and 5.0, respectively, which ranged from 0.125 (S. aureus) to $1.0 \%$ (Shigella dysenterae), with the MBC of 0.25 to $2.0 \%$, respectively. Three times of MIC value of EO (1.5\%) was applied in ground chicken meat seeded with $V$. cholerae ATCC 6395 and was kept at $-20^{\circ} \mathrm{C}$ for 10 days. The test organism was diminished within 24 hours, suggesting that the EO from black cumin is highly active in vivo and could be used as preservative in ground chicken meat. The results of this study provide new dimension of research on EOs from spices against foodborne pathogens in vivo in controlling their growth in meat based food and food products.
\end{abstract}

Key note: Antibacterial activity, essential oil, black cumin, Nagella sativa, foodborne pathogens,

\section{Introduction}

Microbiological food safety is a great concern in every nation irrespective of developed and/or underdeveloped country. Chemical preservatives are being used for long time in food and food items to keep them safe for human consumption. Most of the chemical food preservatives at high concentrations are carcinogens. Use of chemical preservatives in raw fruits, vegetables, milk and meat has been increased day-by-day, which became threat to human health. Recently, scientists and researchers have been trying to find alternatives of chemical preservatives. Natural compounds such as organic extracts of plants and/or essential oils from plants, herbs and spices may be alternatives of chemical preservatives. These natural compounds specially essential oils from herbs and spices have antibacterial and antifungal activity against foodborne pathogens and food spoilage organisms ${ }^{1-9}$. Black cumin (Nigella sativa L.;
Ranunculaceae), is an herbaceous plant. EO from its seeds has been used for centuries against ailments, including infectious diseases ${ }^{10}$. Black cumin seed oil has antibacterial activity against a wide spectrum of organisms-bacteria like Bacillus cereus, $B$. subtilis, B. pumilus, S. aureus, E. coli, S. abony ${ }^{11-17}$. The crude cumin seed extracts and its EO have antibacterial activity ${ }^{18,19}$. Thymoquinone (TQ) an active principle of black cumin seeds oil ${ }^{20,21}$ has antibacterial and antifungal activity ${ }^{22,23}$. The bioactive EO of $N$. sativa seed has been studied in vivo in mice ${ }^{24,25}$. Black cumin seeds have been reported to exhibit many biological effects including anti-parasitic, antibacterial, antifungal, antiviral, antioxidant and anti-inflammatory activities $^{18}$. In addition of antibacterial and antifungal activity it has also other biological properties such as the crude oil and thymoquinone (TQ) extracted from its seeds and oil are effective against many diseases like cancer, cardiovascular complications, 
diabetes, asthma, kidney disease and is effective against cancer in blood system, lung, kidney, liver, prostate, breast, cervix, skin with much safety ${ }^{26}$.

Vibrio cholerae was given priority for this study because, this organisms is the most troublesome for common people of Bangladesh amongst other common foodborne pathogens and no work has been done so fur with this organism. The present study was designed to identify the antibacterial activity of EO from local black cumin seeds and to apply in vivo against $V$. cholerae for controlling this pathogen in ground chicken meat.

\section{Materials and Methods}

Seeds used for essential oil (EO)

Black cumin (Nigella sativa) seeds were used in this study. Seeds were collected from the retail market (Dhaka new market) of Dhaka city.

\section{Test Organisms}

Food borne pathogens such as Staphylococcus aureus (ATCC 25923), Vibrio cholerae (ATCC 6395), Escherichia coli (ATCC 25922), Escherichia coli 0157:H7 (ATCC 12079), and Shigella dysenterae -1 (MJ-84) were used as test organisms in this study. The long-term stock cultures of the test organisms were maintained in $20 \%$ glycerol in cryogenic vials and were kept at $70^{\circ} \mathrm{C}$. Working cultures were maintained on Tryptose soy Agar (TSB) slants and were kept at $4^{\circ} \mathrm{C}$. The TSB slants cultures were periodically transferred onto fresh TSB slants.

\section{Media and Standard reference antibiotic}

Three types of media were used for the determination of antimicrobial activity of the essential oil: Mueller-Hinton Agar (MHA) purchased from Becton, Dickinsm and Company, Tryptose Soya Agar (TSA) purchased from NISSUI, Japan, Mueller-Hinton Broth (MHB), purchased from Becton, Dickinsm and Company. Ciprofloxacillin $(30 \mu \mathrm{g} / \mathrm{disc})$ manufactured by the NISSUI Pharmaceutical Com. Ltd. Japan, was used as reference antibiotic.

\section{Food item for inactivation test}

Ground chicken meat was collected from a reputed market of Dhaka city (Agora).

\section{Extraction of essential oils}

The black cumin seeds were washed in distilled water and airdried. The dried seeds were ground using a mortar and pestle into fine powder. The essential oils (EO) of ground black seeds were extracted using a solvent-solvent extraction method $^{27} .20$ grams of ground seeds were soaked in $80 \mathrm{~m} 1$ of n-hexane and was kept at room temperature for 24 hours and then n-hexane fraction was separated by squeezing through sterilized cheese cloth. The hexane from the fraction was evaporated at $40^{\circ} \mathrm{C}$ using drier, which left mass of organics called concrete. Ethanol (95\%) was added to the concrete, and the material was transferred into a separation funnel, vigorously shaken, and kept for several hours for sedimentation of the ethanol insoluble part, which was mostly wax. The ethanol soluble part was evaporated in a drier at $40^{\circ} \mathrm{C}$ until all of the ethanol was completely evaporated, leaving the absolute EO.

\section{Screening of the antibacterial activity of essential oil}

The antibacterial activity of the EO was evaluated using the discdiffusion assay ${ }^{28}$ against the selected food-borne pathogens. Stock solution of the EO of black cumin was considered as $100 \%$ concentrated. The stock solution was stored at $-20^{\circ} \mathrm{C}$. From this stock solution, $10 \%$ solution was made from which other necessary dilutions of the EO were made with $95 \%$ ethanol.

Discs ( $8 \mathrm{~mm}$ in diameter) made of Whitman filter paper no. I (ADVA-NTEC- Toyo Roshi Kasha, Ltd. Japan) were impregnated with $50 \mu 1$ of each dilution of $\mathrm{EO}$ and were then dried at $40^{\circ} \mathrm{C}$ for overnight in hot air oven and were stored at $4^{\circ} \mathrm{C}$ until use. Discs for negative control were prepared in $95 \%$ ethanol without EO.

One loopful of inoculum of each test organism from cryogenic vial (stock culture of the test organisms) was transferred into 9 $\mathrm{ml}$ of sterile Tryptose Soya Broth (TSB) and grown at $37^{\circ} \mathrm{C}$ for 24 hours. One loopful of the TSB culture was then streaked into the MHA plate and grown at $37 \mathrm{oC}$ for 24 hours. The inocula of the test organisms were prepared by transferring 3 to 4 colonies of the MHA cultures into each $9 \mathrm{ml}$ of sterile Mueller Hinton Broth and incubated in shaking water bath set at $37^{\circ} \mathrm{C}$ for 6 to 12h. The MHB culture was compared with McFarland 0.5 turbidity standards $\left(10^{8} \mathrm{CFU} / \mathrm{ml}\right)^{29}$.

Within 15 minutes after adjusting the turbidity of the inoculum suspension, a sterile cotton swab was dipped into the adjusted suspension. The swab was rotated several times and pressed firmly on the inside wall of the tube above the fluid level. This removed excess inoculum from the swab. The dried surface of a Mueller-Hinton agar plate was inoculated by streaking with swab over the entire sterile agar surface. This procedure was repeated by streaking two more times, rotating the plate approximately $60^{\circ}$ each time to ensure an even distribution of inoculum.

The EO impregnated discs were dispensed onto the surface of the inoculated agar plate using an ethanol dipped and flamed forceps. Each disc was pressed down to ensure complete contact with the agar surface. The discs ware placed so that they are no closer than $24 \mathrm{~mm}$ from centre to centre of the discs. For each plate 5 discs were placed. Plates were kept at refrigeration temperature for $30 \mathrm{~min}$ for better absorption. Discs for negative control as stated earlier were prepared using the same solvent without the EO. The plates were inverted and placed in an incubator at $37^{\circ} \mathrm{C}$ for 24 hours.

\section{Evaluation of plates}

Antibacterial activity was evaluated by measuring the zones of inhibition in $\mathrm{mm}$ (including the $8 \mathrm{~mm}$ disc) with slide calipers 
near the agar surface and the results were recorded. A reading of $8 \mathrm{~mm}$ means no zone of inhibition. Each sample was tested in triplicates and assay in this experiment was repeated thrice.

Effect of temperature on antimicrobial activity of the essential oil

The effects of temperature on antibacterial activity of EO was determined by the methods as described by Lee, Ching-Fu $(2004)^{30}$. Essential oil (3\%) from black cumin seeds were incubated at $37^{\circ} \mathrm{C}, 50^{\circ} \mathrm{C}, 75^{\circ} \mathrm{C}, 100^{\circ} \mathrm{C}$ respectively in a water bath for 30 minute. Then the extracts heated at the different temperatures were cooled down and stored at $4{ }^{\circ} \mathrm{C}$ until use.

After the temperature treatment, the antibacterial activity of the EO was carried out against the test organisms by the disc diffusion method described above ${ }^{28}$. Discs for negative control were prepared in $95 \%$ ethanol without EO.

\section{Effect of $\mathrm{pH}$ on antibacterial activity of the essential oil}

The effect of $\mathrm{pH}$ on the antibacterial activity of the black cumin EO was assayed by the method reported previously with slight modification $^{31,32}$. The buffer solutions used were $50 \mathrm{mM}$ citratephosphate buffer ( $\mathrm{pH} 5.0$ ), 50mM Phosphate buffer ( $\mathrm{pH} 7.0$ ), 20 $\mathrm{mM}$ Tris-HCI buffer ( $\mathrm{pH} 9.0$ ) and $20 \mathrm{mM}$ Glycine- $\mathrm{NaOH}$ buffer (pH 10.0).

From the stock solution, $3 \%$ solution of $\mathrm{pH} 5.0,7.0,9.0$ and 10.0 were prepared by adding measured amount in buffer. Negative control (without EO) was prepared in buffer at different $\mathrm{pH}$.

Discs $(8 \mathrm{~mm})$ were impregnated with $50 \mu \mathrm{l}$ of $3 \% \mathrm{EO}$ of each $\mathrm{pH}$ and were then dried at $40^{\circ} \mathrm{C}$ for overnight in hot air oven and were stored at $4^{\circ} \mathrm{C}$ until use.

The MHA plates were seeded with each test organisms. The prepared different buffered EO discs with negative control discs were dispensed onto the surface of the seeded agar plates. The plates were kept at $4^{\circ} \mathrm{C}$ for $30 \mathrm{~min}$ for better absorption of the sample and then inverted and placed in all incubator set to $37^{\circ} \mathrm{C}$ for 24 hours.

Antibacterial activity was evaluated by measuring the zones of inhibition in $\mathrm{mm}$ (including the $8 \mathrm{~mm}$ disk) for different $\mathrm{pH}$ with slide calipers near the agar surface and the results were recorded. Essential oil from black seeds was tested in triplicates.

Determination of the minimum inhibitory concentration (MIC) and minimum bactericidal concentration (MBC)

The MIC and MBC of the EO of black cumin seeds were determined by two fold dilution method in Mueller-Hinton broth according to Hogue et al. (2008) ${ }^{3}$. The range of concentration used was $4 \%$ to $0.125 \%$ with test organisms. The MIC was done at optimum temperature $\left(50^{\circ} \mathrm{C}\right)$ and optimum $\mathrm{pH}(7.0)$.

The prepared different concentrated EO vials were kept at $37^{\circ}$ for $24 \mathrm{hrs}$. After incubation samples from each vial were streaked on Mueller Hilton agar plates and incubated at $37^{\circ}$ for another 24 hrs. After incubation the plates were observed for MIC and MBC values.

The MIC was considered as the lowest concentration of EO that allow a few growth of bacteria on the plate, above which concentration did not allow growth of the bacteria which was considered as the minimum bactericidal concentration (MBC) of the EO studied.

Use of essential oil from black seeds to inactivate Vibrio cholerae in ground chicken meat

The procedure for inactivation of Vibrio cholerae in ground chicken meat was followed with slight modification described by Hoque et al. $(2008)^{3} .500 \mathrm{~g}$ ground chicken meat sample was sterilized with ethanol and then kept in laminar cabinet under UV radiation for complete evaporation of ethanol from the meat sample. Then $5 \mathrm{~g}$ of the meat sample form was examined for detecting the presence of contaminants in the sample applied for inactivation test. Rest $495 \mathrm{~g}$ of sample was inoculated with Vibrio cholerae to obtain a final concentration of about $\mathrm{I}^{7} \mathrm{CFU} / \mathrm{g}$. Inoculated ground chicken meat samples were uniformly mixed for I min with sterilized spoon. Three times concentrated (1.5\%) black cumin seed oil was then added with half of the meat sample and mixed uniformly for $1 \mathrm{~min}$. Another half part was used as control which is EO free. Then $5 \mathrm{~g}$ each from treated (10 sets) and control meat samples (10 sets) were packed in sterilized Ziploc packs (JMI Bangla Co Ltd) and stored at $-20^{\circ} \mathrm{C}$ for 10 days. Microbiological analysis of control and treated sample was done on 0-10 days of post storage. Each sample was homogenized for 3 minutes in sterilized normal saline using a sterile homogenizer. From this mixture ten-fold serial dilutions $\left(10^{7}\right)$ were prepared and $0.1 \mathrm{ml}$ of each diluent was surface plated on MHA (non-selective) and TCBS (selective). The plates were then incubated at $37^{\circ} \mathrm{C}$ for 24 hours and then presumptive colonies of the test organism were counted and recorded.

\section{Statistical analysis}

The inhibition zones were calculated as means \pm S.D. $(n=3)$. The significance among different data was evaluated by analysis of variance (ANOVA) using Microsoft excel program. Significant differences in the data were established by least significant difference at the $5 \%$ level of significance.

\section{Results}

Screening of the essential oil

Essential oil of Black cumin seeds was found active against Staphylococcus aureus (ATCC 25923), Vibrio cholerae (ATCC 6359), and Shigela dysenteriae-1 (MJ-84) but showed no activity against Escherichia coli (ATCC 25922) and Escherichia coli 0157:H7 (ATCC 12079). The results are recorded in Table1. The highest zone of inhibition $(\mathrm{mm})$ was observed against $S$. aureus (27.0 \pm 0.1$)$ at $10 \%$ concentration of EO, and lowest activity against Shigella dysenterae-1 (13.0 1.0$)$ at 3\% concentration. 
Table 1. The antibacterial activities of essential oil (EO) from black cumin seeds

\begin{tabular}{|c|c|c|c|c|}
\hline \multirow[t]{3}{*}{ Organisms } & \multirow{2}{*}{\multicolumn{4}{|c|}{$\begin{array}{l}\text { Zones of inhibition(in mm) } \\
\text { EO from black cumin seeds }\end{array}$}} \\
\hline & & & & \\
\hline & $3 \%$ & $5 \%$ & $10 \%$ & Ciprofloxacin $(30 \mu \mathrm{g} / \mathrm{disc})$ \\
\hline Vibrio cholerae & $13.8 \pm 1.0$ & $14.5 \pm 1.0$ & $16.25 \pm 0.75$ & $24.83 \pm 0.28$ \\
\hline Escherichia coli & No activity & No activity & No activity & $24.33 \pm 0.28$ \\
\hline
\end{tabular}

Mean diameter of zone of inhibition in mm including the diameter of the disc $8 \mathrm{~mm}$.

Mean \pm S.D. $m m(n=3) ; P<0.05$; ciprofloxacin $(30 \mu \mathrm{g} /$ disc), negative control showed no zone of inhibition.

\section{Effect of temperature on antibacterial activity of EO from black cumin seeds}

The antibacterial activity of EO from black cumin seeds was not destroyed at high temperatures even at $100^{\circ} \mathrm{C}$ for $30 \mathrm{~min}$ treatment. The results are shown in Table 2.

\section{Effect of $\mathrm{pH}$ on antibacterial activity of EO from black cumin seeds}

No significant change of antibacterial activity of EO was found at $\mathrm{pH}$ 5.0, 7.0, and 10.0, but the highest activity was noticed at $\mathrm{pH}$ 7.0. The results are shown in Table 3.
Minimum inhibitory concentration (MIC) and minimum bactericidal concentration (MBC) of EO from black cumin seeds MIC and MBC of EO from black cumin seeds was determined at different concentrations and from the experimental findings it was apparent that $\mathrm{MIC}$ and $\mathrm{MBC}$ values were ranged from 0.125 to $1.0 \%$, and 0.25 to $2.0 \%$, respectively. The results are shown in Table 4 .

\section{Inactivation of Vibrio cholerae in inoculated ground chicken meat with EO from black cumin seeds}

Inactivation test against $V$. cholerae by $1.5 \% \mathrm{EO}$ of black cumin seeds in ground chicken meat stored at $-20^{\circ} \mathrm{C}$ showed that 24

Table 2. Effect of temperatures on antibacterial activity of EO from black cumin seeds

\begin{tabular}{lccccc}
\hline Organisms & \multicolumn{5}{c}{ Zones of inhibition (in mm) } \\
& $25^{\circ} \mathrm{C}$ & $37^{\circ} \mathrm{C}$ & $50^{\circ} \mathrm{C}$ & $75^{\circ} \mathrm{C}$ & $100^{\circ} \mathrm{C}$ \\
\hline Staphylococcus aureus & $15.6 \pm 0.02$ & $17.4 \pm 0.08$ & $17.8 \pm 0.59$ & $14.0 \pm 0.3)$ & $15.0 \pm 0.1$ \\
Vibrio cholerae & $13.43 \pm 0.8$ & $14.5 \pm 1.0$ & $15 \pm 0.52$ & $14 .(\mathrm{N}-0.1$ & $13.0 \pm 0.1$ \\
Shigella dysenteriac-I & $15.5 \pm 0.4$ & $17.3 \pm 1.1$ & $17.2 \pm 0.6$ & $16.0 \pm 0.2$ & $16.0 \pm 0.1$ \\
\hline
\end{tabular}

All the values are mean \pm standard deviation of three determinations

Mean diameter of zone of inhibition in mm including the diameter of the disc $8 \mathrm{~mm}$ Mean \pm S.D. $\mathrm{mm}(\mathrm{n}=3) ; P<0.05$; concentration $=3 \%$, negative control showed no zone of inhibition.

Table-3. Effect of pH on antimicrobial activity of black cumin oil

\begin{tabular}{lcccc}
\hline Organisms & \multicolumn{4}{c}{ zones of inhibition (in mm) } \\
& $\mathrm{pH} 5.0$ & $\mathrm{pH} \mathrm{7.0}$ & $\mathrm{pH} \mathrm{9.0}$ & $\mathrm{pH} 10.0$ \\
\hline Staphylococcus aureus & $17.8 .0 \pm 1.0$ & $18.8 . \pm 0.1$ & $17.6+0.6$ & $17.0+0.5$ \\
Vibrio cholerae & $14.0 \pm 1.0$ & $14.8 \pm 1.0$ & $14.3 \pm 0.7$ & $14.5 \pm 1.0$ \\
Shigella dysenteriae $-I$ & $17.5 \pm 0.8$ & $16.5+0.8$ & $16.3 \pm 0.9$ & $16.2 \pm 0.6$ \\
\hline
\end{tabular}

All the values are mean \pm standard deviation of three determinations

Mean diameter of zone of inhibition in mm including the diameter of the disc $8 \mathrm{~mm}$ Mean \pm S.D. $\mathrm{mm}(\mathrm{n}=3) ; \mathrm{P}<0.05$; concentration $=3 \%$; negative control showed no zone of inhibition.

Table 4. MIC and MBC values of black cumin oil (\%v/v)

\begin{tabular}{lcc}
\hline Organism & MIC $(\%)$ & MBC $(\%)$ \\
\hline Staphylococcus aureus & 0.125 & 0.25 \\
Vibrio cholerae & 0.50 & 1.0 \\
Shigella dysenteriae $-I$ & 1.0 & 2.0 \\
\hline
\end{tabular}


hours EO treated ground chicken meat sample after inoculation in selective medium (TCBSA) showed no growth of the test organism, but in non-selective medium (MHA) $>5$ log reduction of cells were observed, suggesting that there were some injured cells which were able to grow in non-selective medium. The results are shown in Figure 1.

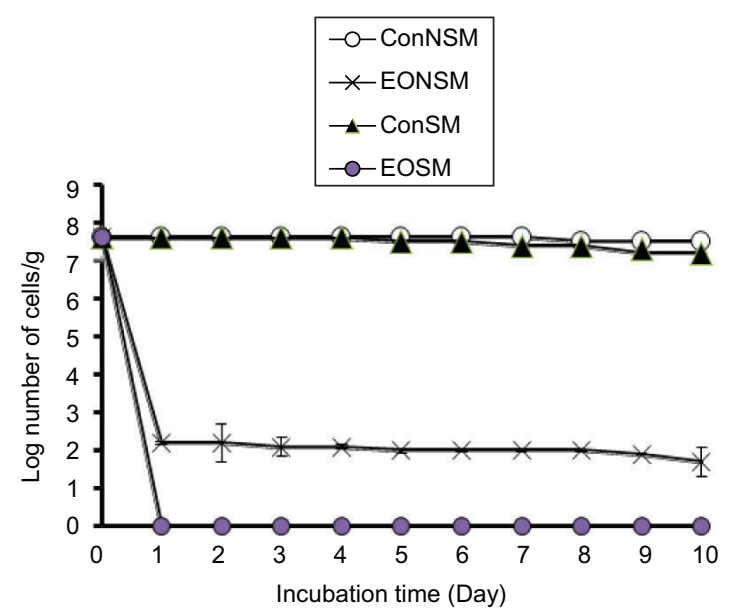

Figure 1. Survival of $V$. cholerae in ground chicken meat exposed to black cumin essential oil (1.5\%) incubated at $-20^{\circ} \mathrm{C}$ for 10 days. Cell counts are represented as mean \pm std. $(n=3)$. Bars indicate error of std. $(p<0.05)$. ConNSM, control in non-selective medium; ConSM, control in selective medium; EONSM, essential oil treated organism in nonselective medium; EOSM, essential oil treated organism in selective medium

\section{Discussion}

The black cumin seeds oil has been thoroughly studied scientifically in the last 3-4 decades and reported to possess a number of medicinal properties like immunomodulatory ${ }^{33}$ and antioxidant ${ }^{34}$ activities. Their crude extracts ${ }^{35}$ and $\mathrm{EO}^{36}$ have been shown to possess activity against several bacteria. Antibacterial properties of $N$. sativa essential oil could be due to the ability of the oil to permeabilize membranes and to destroy cellular integrity of bacteria leading to cell death by necrosis and apoptosis 37 .

In this present study, authors have extracted EO from black cumin seeds in the food Microbiology laboratory, University of Dhaka and applied the EO against foodborne pathogens of four genera prevailed in Bangladesh such as Staphylococcus aureus, Vibrio cholerae, Escherichia coli, Escherichia coli 0157:H7 and Shigella dysenteriae. From the experimental evidence it was revealed that except E. coli and E. coli O157:H7 all other foodborne pathogens are susceptible to $\mathrm{EO}$ of black cumin seeds. $3 \%$ of EO from black cumin seeds showed significant zones of inhibition (in $\mathrm{mm}$ ) against the test organisms in comparison to $30 \mu \mathrm{g} /$ disc of ciprofloxacin (Table 1).

Effect of temperature and $\mathrm{pH}$ on the antibacterial activity of the oil were determined against three susceptible pathogens, and the results from the experiments showed that no significant change of activity were observed against the test organisms at different temperature and $\mathrm{pH}$, suggesting that the EO under study was very stable. This pattern of response of this EO to temperature and $\mathrm{pH}$ has correlated with the findings of Hoque et al. (2008 and 2007) $)^{3,4}$.

MIC and MBC values of the oil under study were observed 0.125 to $1 \%$, and 0.25 to $2 \%$, respectively, which are correlated with the findings of Arici et al. $(2005)^{38}$ who reported MIC and MBC values of EO from black cumin 0.5 to $2 \%$ against lactic acid bacteria and Aeromonas hydrophila.

Essential oil under study was applied in vivo against $V$. cholerae in ground chicken meat at a concentration of three times MIC value $(1.5 \%)$ and from the experimental findings it was revealed that the test organism was did not grow within 24 hours (1day) in selective medium, but allowed growth in non-selective medium at a level of $>5 \log$ reduction, suggesting that the oil is highly potent to reduce the growth of $V$. cholerae in ground chicken meat. The EO from black cumin seeds at dose of $0.3 \mathrm{~g} / \mathrm{kg}$ in mice infected with $S$. aureus and E. coli showed $100 \%$ recovery, suggesting that EO from black cumin seeds would able to use in vivo against pathogens ${ }^{24}$. Findings of this study also correlated with the finding of Hoque et al. $(2008)^{3}$, who worked with cinnamaldehyde an EO from cinnamon against Listeria monocytogenes in vivo in ground chicken meat and findings of Burt $(2004)^{39}$, who applied EO in food against foodborne pathogens.

Activity of EO from black cumin is dose dependant against both Gram positive and Gram negative bacteria ${ }^{24}$, for which at low concentration (i.e. $3 \%$ ) it could not inhibit the growth of $E$. coli and E. coli $\mathrm{O} 157: \mathrm{H} 7$ under this study, suggesting that if the concentration of the oil is increased to some extent, it may inhibit growth of $E$. coli and E. coli $\mathrm{O} 157: \mathrm{H} 7$.

\section{Conclusion}

From the recent investigations, it was known that EO from black cumin seeds is not only used against foodborne pathogens, but also to be used against clinical and environmental infectious pathogens. Essential oil is a cocktail of many compounds; therefore, further studies are necessary to identify the active ingredient of the EO from black cumin ( $N$. sativa L) by using modern techniques available.

\section{References}

1. Shelef LA. 1983. Antimicrobial effects of spices. J. Food Safety. 6: 2944.

2. Zaika LL. 1988. Spices and herbs: Their antimicrobial activity and its determination. J. Food Safety. 9: 97-118.

3. Hoque MM., BariI ML, Inatsu Y, Juneja V Y K and Kawampto S. 2008. Antibacterial activity of cloves and cinnamon extracts against food borne pathogens and spoilage bacteria and inactivation of Listeria monocytogenes in ground chicken meat with their essential oils. Rep. Nat'1 Food Res. 72: 9-21. 
4. Hoque MM., Bari ML, Inatsu Y, Juneja VYK and Kawampto S. 2007. Antibacterial activity of guava (Psidium guajava L.) and neem (Azadirachta indica A. Juss.) extracts against food borne pathogens and spoilage bacteria. Foodborne Patho. and Dis. 4: 481-488.

5. Hoque MM, BariI ML, Inatsu Y and Kawampto S. 2006. Antibacterial activity of some Asian Spices and Herbs against Selected Potent Food Borne Pathogens and Spoilage Bacteria. Proceeding of the JapanBangladesh Joint International Conference on Microbiology Education and the Prospect of Japanese Collaboration in Education and Research. 2: $22-30$.

6. Kaleque MA, Keya CA, Hasan KN, Hoque MM, Inatsu Y and Bari ML. 2016. Use of cloves and cinnamon essential oil to inactivate Listeria monocytogenes in ground beef at freezing and refrigeration temperatures. LWT-Food Sci. and Technol. 74: 219-223.

7. Buchat LR. 1976. Sensitivity of Vibrio parahaemolyticus to spices and organic acids. J. food Sci. 41: 899-902.

8. Huhtanen CN. 1980. Inhibition of Clostridium botulinum by spice extract and aliphatic alcohol. J. food Prot. 43: 195-196.

9. Conner DE and Buchat LR. 1984. Sensitivity of heat-stressed yeast to essential oils of plants. Appl. Enn. Microbiol. 47: 229-233.

10. Salman MT, Khan R A, and Shukla I. 2016. Antibacterial activity of Nigella Sativa Linn. seeds against multiple antibiotics resistant clinical strains of Staphylococcus aureus. Int. Archives of BioMedical and Clin. Res. 2 (3): 96-99.

11. Hadjazi D, Daouadji K L, Reffas FZ.I, Benine ML and Abbouni B. 2015. Antibacterial Activity of the Essential Oils of Nigella sativa L. against Pathogens Bacteria Global J. Biotech. \& Biochem. 10 (2): 100-105.

12. Gurdip S, Marimuthu P, Heluani CS and Catalan D. 2005. C.S.O. J. Sci. Food Agric. 85: 2297-2306.

13. Topozada HH, Mazloum HA and El-Dakhakhny M. 1965. The antibacterial properties of Nigella sativa seeds. Active principle of some clinical applications. J. Egypt. Med. Ass. Suppl, 48: 187-202.

14. Taha S, El-Alfy H, Hamed M., El-Fatatry E and Toama MA. 1975. Isolation and structure Assingnment of an antimicrobial principle from the volatile oil of Nigella sativa L. seeds. Pharmazie. 30: 109-11.

15. Agrawal R, Khaya MD and Shryvastava R. 1979. Antimicrobial anthelmintic activities of the essential oil of Nigella sativa Linn. Indian J. Exp. Boil. 17(11): 1264-1265.

16. Hanafy MS and Hatem ME. 1991. Studies of an antibacterial activity of Nigella sativa (black cumin). J. Ethnopharmacology. 34: 275-278.

17. Hasan CM., Ahsan M and Islam SN. 1989. In-vitro antimicrobial screening of the oils of Nigella sativa seeds. Bangladesh J. Bot. 18: 172-174.

18. Ali BH and Blunden G. 2003. Pharmacological and toxicological properties of Nigella sativa. Phytother. Res. 17(4): 299-305.

19. Mouhajir F and Pedersen JA. 1999. Antimicrobial thymohydroquinones of moroccan Nigella sativa seeds detected by electron spin resonance. Pharmaceutical Biol. 37(5): 391-395.

20. El-Fatatry HM. 1975. Isolation and structure assignment of an antimicrobial principle from the volatile oil of Nigella sativa L. seeds. Pharmazie, 30: 109-111.

21. El-Dakhakhany M. 1963. Studies on the chemical constitution of Egyptian N. sativa L. seeds. Planta Medica., 11: 465-470.
22. Lui M, Koya S, Furuta H and Matsuzaki S .1996. Growth-inhibiting activity of antraquinones and benzoquinones against methicillin-resistant Staphylococcus aureus (MRSA). Dokkyo J. Med. Sci. 23: 85-93.

23. Halawani E. 2009. Antibacterial activity of thymoquinone and hymohydroquinone of Nigella sativa $\mathrm{L}$. and their interaction with some antibiotics. $A B R$ 3: 148-152.

24. Hosseinzadeh H, Bazzaz BSF and Haghi MM . 2007. Antibacterial Activity of Total Extracts and Essential oil of Nigella Sativa L. Seeds in Mice. Pharmacolgyonline 2: 429- 435.

25. Entela H, Stefano M, Vilma T and Silvia V. 2012. Antimicrobial and antifungal activity assesment of Nigella sativa essential oils. WASET. 66: $1198-1120$.

26. Khan MA, Han-chun Chen, Tania M and Zhang Dian-zheng. 2011. Anticancer activities of Nigella sativa (Black cumin). Afr $J$ Tradit Complement Altern Med. 8: 226-232.

27. Wilson CL, Solar JM, El Ghaouth A, and Wisniewski ME. 1997. Rapid evaluation of plant extracts and essential oils for antifungal activity against Botrytis cinerea. Plant Dis. 81: 204-210.

28. Bauer AW, Kirby WMM, Sherris JC and Truck M. 1066. Antibiotic sensitivity testing by a standardized single disk diffusion method. Am. J. Clin. Pathol. 45: 157-160.

29. Jorgensen JH, Turnide JD and Washington JA. 1999. Antibacterial susceptibility tests: dilution and disk diffusion methods. In: Murry P R, Pfaller MA, Tcnover F C, Baron E J, Yolken R H, editors. Manual of Clinical Microbiology, 7 th ed. Washington DC, ASM Press. pp 15261543.

30. Lee, Ching-Fu, Chien-Kuo H and Jya-Li T. 2004. In vitro inhibitory activity of Chinese leek extract against Campylohacter species. Int. J. Food Microbiol., 94: 169-174.

31. Shabata K, Yho A and Hengo AY. 1995. Bacterial activity of spices antimicrobial agent against Helicobacter pylori under acidic condition. Antimicrob. Agents. Chemother. 39: 1295-1299.

32. Ohono T, Kita M, Yamaka Y, Imamura T, Mitsufuji S, Kodama T, Kashima $\mathrm{K}$ and Imanishi J. 2003. Antimicrobial activity of essential oils against Helicobacter jejuni. Helicobacter. 8: 207-215.

33. Alshatwi AA. 2014. Bioactivity-guided identification to delineate the immunomodulatory effects of methanolic extract of Nigella sativa seed on human peripheral blood mononuclear cells. Chin J Integr. Med. Mar 2. (Epub ahead of print).

34. Kushwah DS, Salman MT, Singh P, Verma VK and Ahmad AA. 2014. Protective Effects of Ethanolic Extract of Nigella sativa Seed in Paracetamol Induced Acute Hepatotoxicity In vivo. Pakistan J. Biol. Sci. 17(4): 517-522.

35. Ali NA, Julich WD, Kusnick C and Lindequist U. 2001. Screening of Yemeni medicinal plants for antibacterial and cytotoxic activities. $J$ Ethnopharm. 74(2): 173-9.

36. Salman MT, Khan RA, Shukla I. 2008. Antimicrobial activity of Nigella sativa Linn. seed oil against multi-drug resistant bacteria from clinical isolates. Nat. Product Radiance. 7(1): 10- 4.

37. Bakkali F, Averbeck S, Averbeck D and Idaomar M. 2007. Biological effects of essential oils. Food and Chem. Toxico. 46: 446-475.

38. Arici M, Sagdic O and Gecgel U. 2005. Antibacterial effect of Turkish black cumin (Nigella sativa L.) oils. Grasas y Aceites. 56(4): 259-262.

39. Burt S. 2004. Essential oils: their antibacterial prop-erties and potential applications in foods-a review. Int. J. Food Microbiol. 94: 223-253. 